\title{
Size-controlled preparation of fluorescent gold nanoparticles using pamoic acid
}

\author{
Md. Abdul Aziz ${ }^{1}$ - Jong-Pil Kim ${ }^{2}$ - M. Nasiruzzaman Shaikh ${ }^{1}$ - Munetaka Oyama ${ }^{3}$. \\ Fatai Olawale Bakare ${ }^{1} \cdot$ Zain Hassan Yamani $^{1}$
}

Published online: 15 July 2015

(C) The Author(s) 2015. This article is published with open access at SpringerLink.com

\begin{abstract}
We previously showed that pamoic acid (PA) could be utilized as a reducing and capping reagent for preparing monodispersed gold nanoparticles (AuNPs) with diameters of $10.8 \mathrm{~nm}$. Here, we show that the size of these PA-capped AuNPs can be varied in a controlled manner by changing the $\mathrm{pH}$ used in the preparation process. By changing the added amount of $\mathrm{NaOH}$ in the PA solution before mixing with $\mathrm{HAuCl}_{4}$, several types of AuNPs were prepared at different $\mathrm{pH}$ values. The absorption spectra showed a red shift of the characteristic peak of the AuNPs with decreasing $\mathrm{pH}$, indicating the formation of larger AuNPs. The TEM results confirmed this relationship between AuNP size and $\mathrm{pH}$, and the zeta potentials indicated that the AuNPs capped with PA were more stable than the AuNPs prepared by citrate reduction method. Furthermore, the PA-capped AuNPs showed much higher fluorescence intensities than those of citrate-capped AuNPs, which is due to the fluorescence of PA. The sizes of PA-capped spherical AuNPs could also be controlled by a seed-mediated growth approach. However, the original PA-
\end{abstract}

Md. Abdul Aziz

maziz@kfupm.edu.sa

1 Center of Research Excellence in Nanotechnology, King Fahd University of Petroleum and Minerals, Dhahran 31261, Saudi Arabia

2 Surface Properties Research Team, Korea Basic Science Institute Busan Center, Busan 609-735, South Korea

3 Department of Material Chemistry, Graduate School of Engineering, Kyoto University, Nishikyo-ku Kyoto 615-8520, Japan capped AuNPs, with diameters of $10.8 \mathrm{~nm}$, exhibited the highest fluorescence intensities among the various types of PA-capped AuNPs that were grown. In addition to conferring fluorescence properties to the AuNPs, the capping by PA also provided the nanoparticles with carboxylate groups.

Keywords Hydrogen tetrachloroaurate $\cdot$ Pamoic acid $\cdot \mathrm{pH}$. Carboxylate-functionalized gold nanoparticles .

Seed-mediated growth $\cdot$ Zeta potential $\cdot$ Fluorescence

\section{Introduction}

Gold nanoparticles (AuNPs) have attracted much attention due to their wide application in various research fields such as drug delivery, electrocatalysis, sensors, fuel cells, organic photovoltaics, catalysis, and glass coloring [1-8]. The broad range of applications of AuNPs can be attributed to their unique properties, which are tunable with their size, stabilizing or capping agents [1-3, 7-10]. Various methods have been developed for the preparation of AuNPs. The gold precursor is commonly reduced with reductants such as ascorbic acid, sodium borohydride and citrate, and the selection of capping agents significantly affects the formation of AuNPs [11-17]. In addition, preparation methods in which a reagent acts simultaneously as a reducing and capping reagent have been proposed [11-13, 18-20]. Any method for the synthesis of AuNPs with a narrow size dispersion, i.e., good monodispersity, would be important from a view of the preparation of nanomaterials. 


\section{Structure 1}

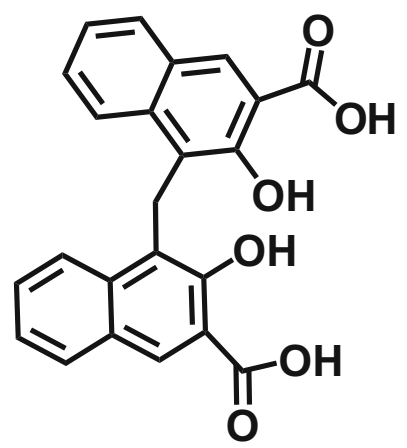

We previously reported a simple method for the preparation of AuNPs using pamoic acid (PA; 4,4'-methylene-bis(3-hydroxy-2-naphthalene carboxylic acid) (structure 1) with $\mathrm{NaOH}$ at room temperature [21]. Although PA is insoluble in water, it can be dissolved in the presence of $\mathrm{NaOH}$ and functions as a capping and reducing reagent to form AuNPs. The AuNPs formed in this way have good monodispersity with diameters of $10.8 \pm 1.2 \mathrm{~nm}$ and carboxylate functional groups that originated from the PA. This is an interesting example of stable, monodispersed, carboxylate-functionalized AuNPs being prepared without the use of thiols. These PAcapped AuNPs with diameters of about $10.8 \mathrm{~nm}$ are denoted as original AuNPs in the rest of the manuscript.

Modifying the size of PA-capped AuNPs in a controlled manner, however, was not explored in our earlier work [21]. Therefore, one of the aims for the present work was to control the sizes of AuNPs during the chemical preparation with PA. We found that the amount of $\mathrm{NaOH}$, i.e., $\mathrm{pH}$, affected their average size. Changes in the size of the AuNPs were determined from UV-Vis absorption spectra and TEM images. In addition, as a fine tuning method of the size, a seed-mediated growth treatment from AuNPs of $10.8 \mathrm{~nm}$ was examined.

Another aim of the currently reported work was to show the fluorescence properties of PA-capped AuNPs, which had not been described in our previous work [21]. Since PA is a fluorescent molecule [22], capping with PA is expected to provide significant fluorescence properties to AuNPs in addition to providing the carboxylate functional groups. Fluorescent AuNPs could be utilized in sensors for the purpose of heavy metal detection, controlling the growth of pathogens, imaging, etc. [23-28]. Some methods have already been developed to prepare fluorescent AuNPs, such as reduction of gold precursor with $\mathrm{NaBH}_{4}$ in the presence of 11-mercaptoundecanoic acid in toxic organic solvent, reduction of gold precursor with biomolecules like bovine serum albumin (BSA) and etching pre-synthesized AuNPs with hyperbranched and multivalent polymers [23, 29, 30]. However, the simple preparation with PA as a capping agent and reducing agent should be an effective approach for preparing fluorescent AuNPs having good monodispersity. To verify this hypothesis, in the present work, the fluorescence properties of PA-capped AuNPs were studied together with those of the AuNPs grown at different values of $\mathrm{pH}$ or using the seed-mediated growth approach.

\section{Experimental}

\section{Materials}

Hydrogen tetrachloroaurate trihydrate $\left(\mathrm{HAuCl}_{4} \cdot 3 \mathrm{H}_{2} \mathrm{O}\right)$, pamoic acid (PA), sodium hydroxide, and sodium citrate ( $\mathrm{Na}_{3}$-citrate) dihydrate were supplied by Sigma-Aldrich (http://www.sigmaaldrich.com/united-states.html). All solutions were prepared with ultrapure water obtained from a water purification system (Barnstead $^{\mathrm{TM}}$ Nanopure $^{\mathrm{TM}}$, Themoscientific, 7148, USA (www.thermo.com/purewater).

\section{Synthesis of AuNP by controlling the alkali}

The original PA-capped AuNPs were synthesized according to our earlier report [21]. Briefly, a clear solution of $2 \mathrm{mM}$ disodium salt of PA $\left(\mathrm{Na}_{2}-\mathrm{PA}\right)$ was prepared by sonication of $7.9 \mathrm{mg}$ of PA and $40 \mu \mathrm{l}$ of $1.0 \mathrm{M} \mathrm{NaOH}$ (aq.) in $10 \mathrm{ml}$ water. Next, excess $100 \mu \mathrm{l}$ of $1.0 \mathrm{M} \mathrm{NaOH}$ was added to the clear solution and subsequently sonicated for $1 \mathrm{~min}$. Afterward, $10 \mathrm{ml}$ of $1.34 \mathrm{mM} \mathrm{HAuCl}_{4}$ (aq.) was added to the above solution under sonication, and the sonication was continued for $15 \mathrm{~min}$. Similarly, the different sizes of PA-capped AuNPs were obtained by simply varying the excess volume of $1.0 \mathrm{M} \mathrm{NaOH}$ in this study.

\section{Controlling the size of the AuNP by seed mediated growth approach}

Here, the original PA-capped AuNPs were used as seeds. Five milliliters or $2.5 \mathrm{ml}$ of the AuNP seed solution were added to a mixture of $10 \mathrm{ml}$ of $1.34 \mathrm{mM} \mathrm{HAuCl}_{4}$ (aq.) and $10 \mathrm{ml}$ of $2 \mathrm{mM}$ $\mathrm{Na}_{2}$-PA (aq.) under stirring conditions (200 rpm), and stirring was continued for $24 \mathrm{~h}$ to complete the growth of the AuNPs.

\section{Synthesis of AuNP using the classical citrate method}

The citrate-capped AuNPs were synthesized with little modification of the previously reported procedure [31]. In brief, $100 \mathrm{ml}$ of $1 \mathrm{mM} \mathrm{HAuCl}_{4}$ was reduced by $10 \mathrm{ml}$ of $38.8 \mathrm{mM}$ $\mathrm{Na}_{3}$ citrate in refluxing conditions to obtain the Au colloids.

\section{Characterization and instrumentation}

The absorption spectra were recorded using a UV-Vis spectrophotometer (JASCO V-670) (http://www.jascoinc.com/ spectroscopy/v-670-uv-vis-spectrophotometer). All AuNP solutions were first diluted with ultrapure water to arrive at the 
same $0.1663 \mathrm{mM}$ concentration of Au prior to recording their UV spectra. The $\mathrm{pH}$ of the gold nanoparticle solutions were recorded using a Dual Cannel pH meter, XL60, Fisher Scientific. Transmission electron microscopic (TEM) images were obtained using a JEM-2011 (JEOL corp.) at the Korea Basic Science Institute, Busan Center, Korea. Field emission scanning electron microscopy (FE-SEM) images were obtained using a field emission SEM (TESCAN LYRA 3, Czech Republic).

Fluorescence measurements were performed using spectrofluorometer (Fluorolog FL3-iHR, HORIBA Jobin Yvon, France) (http:/www.horiba.com/us/en/scientific/products/ fluorescence-spectroscopy/steady-state/fluorolog/fluorolog-rour-modular-spectrofluorometer-522/). Zeta potential was measured using a ZEN 2600, Malvern Instruments Ltd, UK. Before recording the fluorescence spectra and zeta potential, the AuNP solutions were centrifuged to remove the unbound PA and subsequently re-dispersed in ultrapure water to obtain the same $0.1663 \mathrm{mM}$ concentration of $\mathrm{Au}$ in each sample.

\section{Results and discussion}

The capping molecules have an influence on the properties of AuNPs. In the classical citrate method, citrate acts as a reductant as well as a capping molecule, whereas in our developed method, PA takes on that role. We therefore systematically recorded the UV spectra of the aqueous solutions of the individual reactants, i.e., $0.25 \mathrm{mM} \mathrm{Na}_{3}$-citrate (Fig. 1A (a)), $0.25 \mathrm{mM} \mathrm{Na}_{2}$-PA (Fig. $1 \mathrm{~A}(\mathrm{~b})$ ), and $0.1663 \mathrm{mM} \mathrm{HAuCl}_{4}$ (Fig. 1A (c)), before starting the preparation of AuNPs. The UV spectrum of $\mathrm{Na}_{3}$-citrate did not show any absorption in the entire tested range of wavelengths (280-700 nm). On the other hand, $\mathrm{Na}_{2}$-PA showed significant absorbance, with absorption peaks at 285, 300, and $363 \mathrm{~nm}$ (Fig. $1 \mathrm{~A} \mathrm{(b)),} \mathrm{and} \mathrm{HAuCl}_{4}$ showed an absorption peak at $289 \mathrm{~nm}$ (Fig. 1A (c)) due to metal-to-ligand charge transfer. This $\mathrm{HAuCl}_{4}$ peak disappeared after reducing the gold ion with $\mathrm{Na}_{3}$-citrate (Fig. 1B (a)), and a new absorption peak appeared at $519 \mathrm{~nm}$, which is a characteristic peak of AuNPs with diameters of about $13 \mathrm{~nm}$. The optical photograph (a) in Fig. 1B inset shows the red color of the AuNP solution prepared by this citrate reduction method.

To check the effect of excess volume of $1 \mathrm{M} \mathrm{NaOH}$ on the preparation of PA-capped AuNP, initially, we prepared the original AuNP according to our earlier report. Briefly, excess $100 \mu \mathrm{l}$ of $1 \mathrm{M} \mathrm{NaOH}$ was added to the $\mathrm{Na}_{2}$-PA solution. Next, the solution was mixed with $1.34 \mathrm{mM} \mathrm{HAuCl}_{4}$ (aq.) under sonication conditions, and sonication was continued for $15 \mathrm{~min}$. During this period, the color of the solution changed from yellow to blackish, and then deep red, which indicated the formation of the AuNPs. Next, the reaction mass was stored undisturbed for $60 \mathrm{~min}$ to allow the complete formation of the AuNPs. The optical photograph $b$ in Fig. 1B inset shows the deep red final color of the AuNP solution prepared in this way. However, the reaction rate decreased when we decreased the excess volume of $1 \mathrm{M} \mathrm{NaOH}$, even though the other steps in the procedure were similar to those of our earlier report [21]. One day was required to complete the reaction after the 15 min of sonication when excess $40 \mu \mathrm{NaOH}$ was used, whereas 2 and 3 days were, respectively, required when excess 20 - and 5- $\mu$ l volumes of $1 \mathrm{M} \mathrm{NaOH}$ were used. The cause of the slow reaction rate might be due to the $\mathrm{pH}$ of the reaction mass, as the $\mathrm{pH}$ of the solution of synthesized AuNPs decreased as expected when decreasing the excess volume of $\mathrm{NaOH}$ (Table 1). Reddish-violet, reddish-blue and brown were the final colors observed for the synthesized AuNPs when using 40,20, and $5 \mu$ l excess volumes of $1 \mathrm{M} \mathrm{NaOH}$, respectively (photographs c, d, and e in the inset of Fig. 1B). The difference in colors indicates the different shapes or sizes of the synthesized AuNPs. Note that all the synthesized AuNPs were stable and did not precipitate, except for the case when excess $5 \mu \mathrm{l}$ of $1 \mathrm{M} \mathrm{NaOH}$ was used. In this case, the prepared AuNPs precipitated gradually. These precipitated AuNPs nevertheless rapidly redispersed with simple manual shaking. This trend was also found for the commercially available large AuNPs as well.

In addition, the wavelength of the characteristic AuNP absorption peak (at $>500 \mathrm{~nm}$ ) was found to increase when decreasing the excess volume of $1 \mathrm{M} \mathrm{NaOH}$ (aq.) solution (Fig. 1B). This result indicates that the size of the AuNPs
Fig. 1 A UV-Vis spectra of the aqueous solution of $0.25 \mathrm{mM} \mathrm{Na}_{3}$ -citrate $(a), 0.25 \mathrm{mM} \mathrm{Na}_{2}-\mathrm{PA}(b)$, and $0.1675 \mathrm{mM} \mathrm{HAuCl}_{4}(c)$. B UV-Vis spectra of the citratecapped AuNP (a), PA-capped AuNP prepared by using different volumes of excess $1 \mathrm{M} \mathrm{NaOH}(b-$ e). $100(b), 40(c), 20(d)$, and $5 \mu \mathrm{l}$ (e) of excess $1 \mathrm{M} \mathrm{NaOH}$. Inset of B shows the corresponding photographs
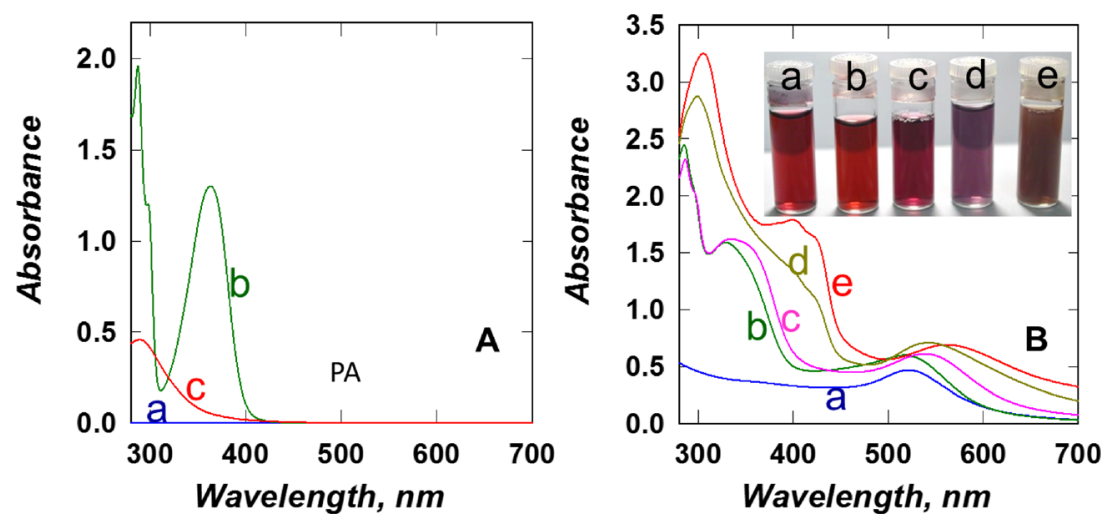
Table 1 The observed UV absorption peaks and $\mathrm{pH}$ values of the PA-capped AuNP solutions prepared using different volumes of $1 \mathrm{M} \mathrm{NaOH}$

\begin{tabular}{llll}
\hline Number & Excess volume of $1 \mathrm{M} \mathrm{NaOH}(\mu \mathrm{L})$ & Absorption peak $(\mathrm{nm})$ & $\mathrm{pH}$ \\
\hline $\mathrm{b}$ & 100 & $517,285,329$, & 8.12 \\
$\mathrm{c}$ & 40 & $538,335,285$ & 5.25 \\
$\mathrm{~d}$ & 20 & 542,299 & 4.50 \\
$\mathrm{e}$ & 5 & $562,399,305$ & 3.72 \\
\hline
\end{tabular}

increased when the excess volume of $1 \mathrm{M} \mathrm{NaOH}$ (aq.) was decreased. The lower wavelength $(<500 \mathrm{~nm})$ absorption peaks also differed for the PA-capped AuNPs produced using different volumes of $1 \mathrm{M} \mathrm{NaOH}$ (Fig. 1B). The absorption peaks of different PA-capped AuNPs prepared by controlling the volume of $1 \mathrm{M} \mathrm{NaOH}$ are summarized in Table 1.

Figure 2 shows TEM images of the synthesized AuNPs. The TEM image of citrate-capped AuNPs (Fig. 2a) shows them to be mono-disperse with an average size of $11.37 \pm$ $0.91 \mathrm{~nm}$, which is smaller than that reported previously [31]. Figure $2 b$ shows the TEM images of original PA-capped AuNPs, which were prepared exactly according to our original method [21]. The $\mathrm{pH}$ of this AuNP solution was 8.12. At this $\mathrm{pH}$, the average size of the AuNPs was observed to be $10.7 \pm$ $0.8 \mathrm{~nm}$, which is the same as that from our previous report $(10.8 \pm 1.2 \mathrm{~nm})[21]$. These results indicate that our developed
Fig. 2 TEM images of the AuNPs prepared in different ways as described in corresponding a-e of Fig. 1B legend. The image in d is magnified in the inset
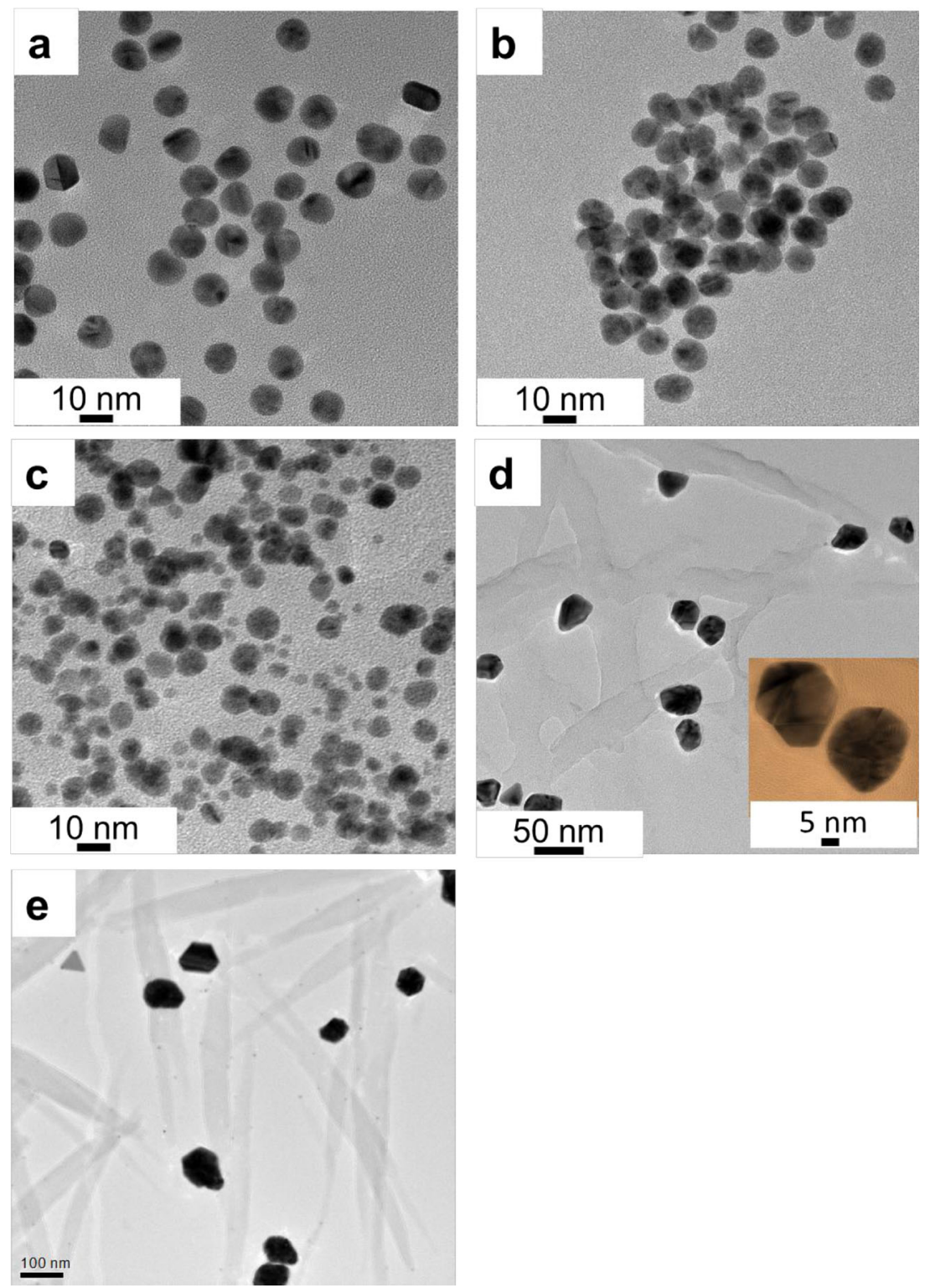
method is reproducible. Figure 2c-e shows the TEM images of PA-capped AuNPs prepared using 40, 20, and $5 \mu \mathrm{l}$ excess volumes of $1 \mathrm{M} \mathrm{NaOH}$, respectively, and the $\mathrm{pH}$ values of the corresponding AuNP solutions were 5.25, 4.50, and 3.7, respectively. At $\mathrm{pH}$ values of 8.1 and 5.25, the AuNPs were observed to be spherical (Fig. 2b, c). However, at pH 5.25, the prepared AuNPs were totally irregular in size (Fig. 2c). As a result, these AuNPs were not further characterized. On the other hand, the AuNPs formed at $\mathrm{pH} 4.5$ displayed different shapes (some being triangular, others being rectangular, pentagonal, or rod type, etc.) (Fig. 2d and its inset). The average size of these AuNPs was measured to be $31.1 \pm 3.68 \mathrm{~nm}$. The synthesized AuNPs at $\mathrm{pH} 3.7$ were observed to be the biggest among the synthesized AuNPs, with an average size of $75.64 \mathrm{~nm}$ (Fig. 2e). The formed AuNPs at pH 3.7 were clearly observed to be triangular, pentagonal, and hexagonal in the TEM images (Fig. 2e). The FE-SEM images showed that the 31.1 and $75.64 \mathrm{~nm}$ AuNPs are approximately three-dimensional (data are not shown).

Zeta potentials were measured for the synthesized AuNPs (Fig. 3). The zeta potential is an important parameter for assessing the stability of colloidal NPs, and highly stable colloidal NPs are generally required for practical purposes. Before recording the zeta potential, all the unbounded citrates or pamoates were removed by centrifugation, and the precipitated AuNPs were re-dispersed in deionized water. All PAcapped AuNPs (b, d, and e in Fig. 3) showed higher zeta potentials than did the citrate-capped AuNP (a in Fig. 3), and the highest zeta potential (d in Fig. 3) was observed for AuNPs whose average diameter was $31.1 \pm 3.8 \mathrm{~nm}$. The good stabilities of the PA-capped AuNPs are due to the presence of the two carboxylic groups of PA.

Before comparing the fluorescence properties of the citratecapped AuNPs and PA-capped AuNPs, the fluorescence properties of $\mathrm{Na}_{3}$-citrate and $\mathrm{Na}_{2}-\mathrm{PA}$ were compared. For a proper comparison, the excitation wavelengths $\left(\lambda_{\mathrm{ex}}\right)$ of both

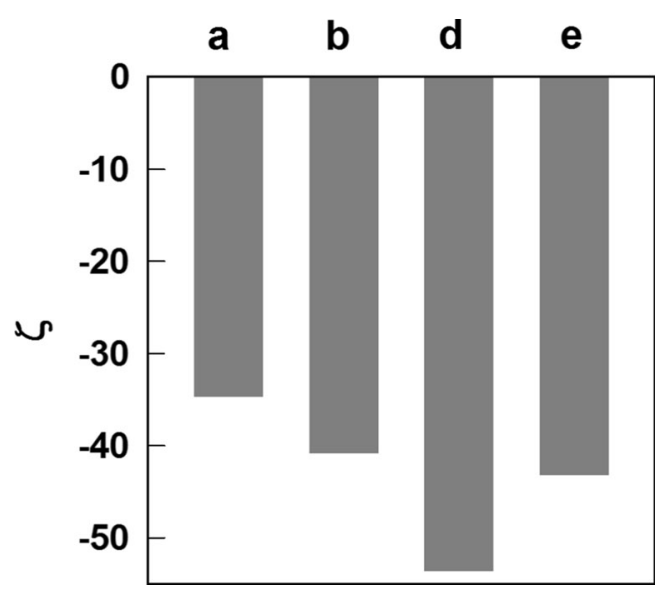

Fig. 3 Plot of the zeta potentials of the different AuNPs described in Fig. 1B reductants were selected basically according to the absorption peaks of $\mathrm{Na}_{2}-\mathrm{PA}$ (Fig. $1 \mathrm{~A}$ (b)) as $\mathrm{Na}_{3}$-citrate showed no absorption peaks in the entire tested wavelength zone. The excitation wavelengths for the original PA-capped AuNP and citrate-capped AuNP were similarly selected according to the absorption peaks of the original PA-capped AuNP (Fig. 1B (b) and see below). Figure 4a, b shows the emission spectra of $0.25 \mathrm{mM} \mathrm{Na}_{3}$-citrate (aq.) and $0.25 \mathrm{mM} \mathrm{Na}_{2}-\mathrm{PA}$ (aq.), respectively. The emission spectra of $\mathrm{Na}_{2}-\mathrm{PA}$ were recorded with excitation for $30 \mathrm{~s}$ at wavelengths of 285, 300, and $363 \mathrm{~nm}$ (Fig. 4b). The emission spectra of $\mathrm{Na}_{3}$-citrate were recorded with excitation at a wavelength of $308 \mathrm{~nm}$ as well as the wavelengths used for $\mathrm{Na}_{2}-\mathrm{PA}$, as the fluorescence properties of commercially available AuNP with excitation at $308 \mathrm{~nm}$ has been reported [32]. Also, the excitations at $308 \mathrm{~nm}$ were performed to record the emission spectra of citratecapped AuNPs and original PA-capped AuNPs for proper comparison.

Each of the emission spectra of $\mathrm{Na}_{2}-\mathrm{PA}$, resulting from the different excitation wavelengths, show a broad envelope of intensity stretching from 420 to $720 \mathrm{~nm}$ with the peak centered at $525 \mathrm{~nm}$. The most intense fluorescence from $\mathrm{Na}_{2}-\mathrm{PA}$ was observed with excitation at $363 \mathrm{~nm}$. On the other hand, very low fluorescence intensity was observed for $\mathrm{Na}_{3}$-citrate, which is expected, as no absorption of light was observed in the UV experiment (Fig. 1A (a)). The emission peak from $\mathrm{Na}_{3}$-citrate was centered at $416 \mathrm{~nm}$ for all excitation wavelengths except $363 \mathrm{~nm}$. At the $363-\mathrm{nm}$ excitation wavelength, the Raman scattering peak of water appears at $414.1 \mathrm{~nm}$. As a result, it was not possible to obtain the weak emission peak from $\mathrm{Na}_{3}$-citrate with a $363 \mathrm{~nm} \lambda_{\text {ex}}$.

Figure $4 \mathrm{c}$ shows the emission spectra of citrate-capped AuNPs with different excitation wavelengths, and emission peaks appeared at 411, 413, and $430 \mathrm{~nm}$ with excitation at 285, 308, and $329 \mathrm{~nm}$, respectively. The highest intensity appeared with excitation at $308 \mathrm{~nm}$. These emission spectra might result from excitation of the surface plasmon coherent electronic motion as well as the $\mathrm{d}$ electrons [32]. Figure $4 \mathrm{~d}$ shows the emission spectra of the original PA-capped AuNP, and the emission peak was centered at the same position (408 nm) whether the excitation wavelength was 285, 308, or $329 \mathrm{~nm}$. The highest intensity appeared with excitation at $329 \mathrm{~nm}$ (Fig. 4d), which is one of the absorption peaks of this AuNP (Fig. 1B (b)). The emission peak intensity of this original PA-capped AuNP is 17 times higher than that of the citrate-capped AuNP. These experiments clearly indicate that the AuNPs prepared with PA possess significantly better fluorescence properties than do the AuNPs prepared by the conventional citrate method.

We also measured the emission spectra of PA-modified AuNPs whose average diameters were 31.1 and $75.6 \mathrm{~nm}$ (data not shown), here using excitation wavelengths selected according to the corresponding UV absorption peaks of their 
Fig. 4 Fluorescence spectra of $0.25 \mathrm{mM}$ tri-sodium citrate (a), $0.25 \mathrm{mM} \mathrm{Na}_{2}-\mathrm{PA}$ (b), citratecapped AuNP (c), and PA-capped AuNP (d) with $30 \mathrm{~s}$ of excitation at the wavelength $(\mathrm{nm})$ indicated in the respective figure. The citrate-capped AuNP and PAcapped AuNP were prepared as described in Fig. 1B (a) and (b), respectively
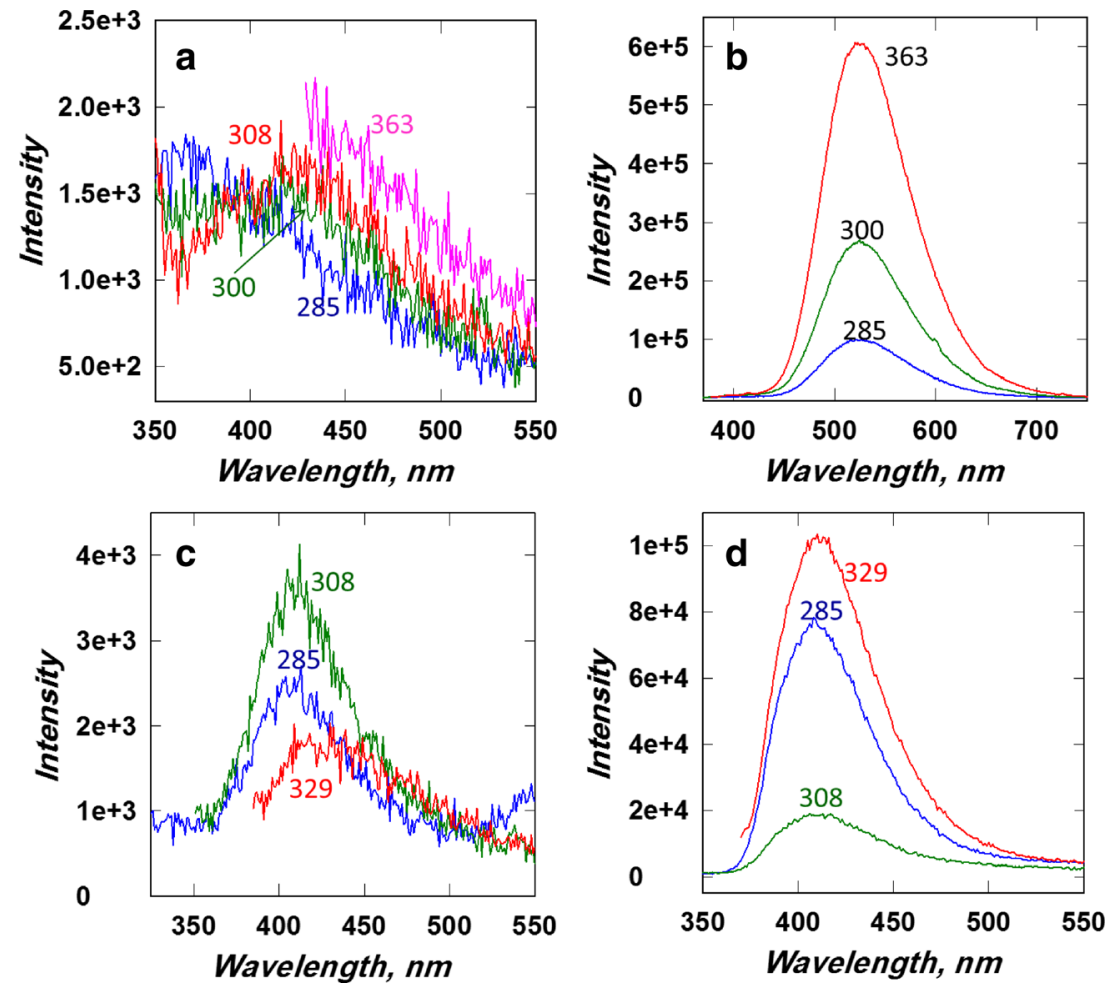

respective PA-capped AuNPs (Fig. 1B (d) and (e)) and hence different than those used above for the original AuNP. Excitation with $399 \mathrm{~nm}$ showed the most intense emission peak centered at $500 \mathrm{~nm}$ for both cases. This results is expected since the 75.6-nm diameter AuNP showed an absorption peak at $399 \mathrm{~nm}$ (Fig. 1B (e)), and the 31.1-nm diameter AuNP also showed high absorption at $\sim 399 \mathrm{~nm}$ (Fig. 1B (d)). Both of these PA-capped AuNPs showed higher fluorescence than that of the citrate-capped AuNPs. Yet, the fluorescence intensity of the original PA-capped AuNP was observed to be the highest among the tested AuNPs (Fig. 5). The reason of the highest

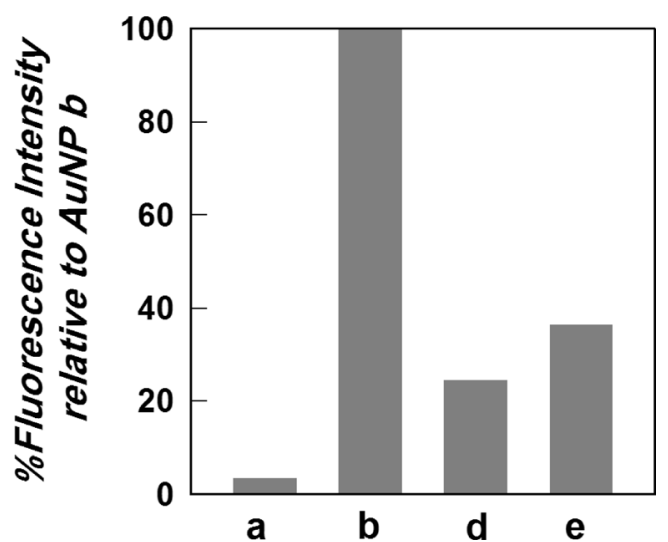

Fig. 5 Relative fluorescence intensities of different AuNPs. Several fluorescence spectra of each AuNP were measured with excitation at different wavelengths. The highest fluorescence signal of each AuNPs was used for comparison. The preparation of different AuNPs is described as in Fig. 1B fluorescence intensity of the original PA-capped AuNP might be the smallest sizes (i.e., largest surface area for the same concentration of $\mathrm{Au}$ ) among the PA-capped AuNPs. This largest surface area is responsible to capture the largest amount of PA which acts as fluorophore. Later, this phenomenon will be confirmed again with comparison of florescence properties among the different sizes of spherical PAcapped AuNPs. Besides, the reason of higher florescence intensity of the 75.6-nm diameter AuNP compared to the 31.1-nm diameter AuNP is not identified yet. It might be sharper shape (triangular, pentagonal, and hexagonal) of the 75.6-nm diameter AuNP compared to the 31.1-nm diameter AuNP. It is reported that the shape of the metal nanoparticles affects the fluorescence intensity of fluorophore-attached metal nanoparticles due to the variation of fluorophore-metal nanoparticle interaction $[33,34]$.

In separate experiments, the size-controlled preparations of spherical AuNPs were developed using a seed-mediated growth approach. Here, the original PAcapped AuNPs (5 or $2.5 \mathrm{ml}$ ) were poured as seeds into a growth solution (mixture of $10 \mathrm{ml}$ of $1.34 \mathrm{mM}$ $\mathrm{HAuCl}_{4}$ and $10 \mathrm{ml}$ of $2 \mathrm{mM} \mathrm{Na}$-PA) while stirring at $200 \mathrm{rpm}$, and stirring was continued for $24 \mathrm{~h}$. After treatment with the growth solution, spherical shaped AuNPs with diameters of $15.5 \pm 1.4 \mathrm{~nm}$ (Fig. 6f and $\mathrm{f}^{\prime}$ ) and $19.3 \pm 1.4 \mathrm{~nm}$ (Fig. $6 \mathrm{~g}$ and $\mathrm{g}^{\prime}$ ) were observed when using 5 and $2.5 \mathrm{ml}$ of AuNP seeds, respectively. This result indicates that the $\mathrm{AuCl}_{4}{ }^{-}$chemically reduced on 
Fig. 6 TEM images of the AuNPs prepared by injecting $5 \mathrm{ml}$ (f) and $2.5 \mathrm{ml}$ (g) of original PAcapped AuNPs into an aqueous mixture of $10 \mathrm{ml}$ of $1.34 \mathrm{mM}$ $\mathrm{HAuCl}_{4}$ and $10 \mathrm{ml}$ of $2 \mathrm{mM} \mathrm{Na}_{2}$ PA. $\mathbf{f}^{\prime}, \mathbf{g}^{\prime}$ are the magnified views of $\mathbf{f}$ and $\mathbf{g}$, respectively
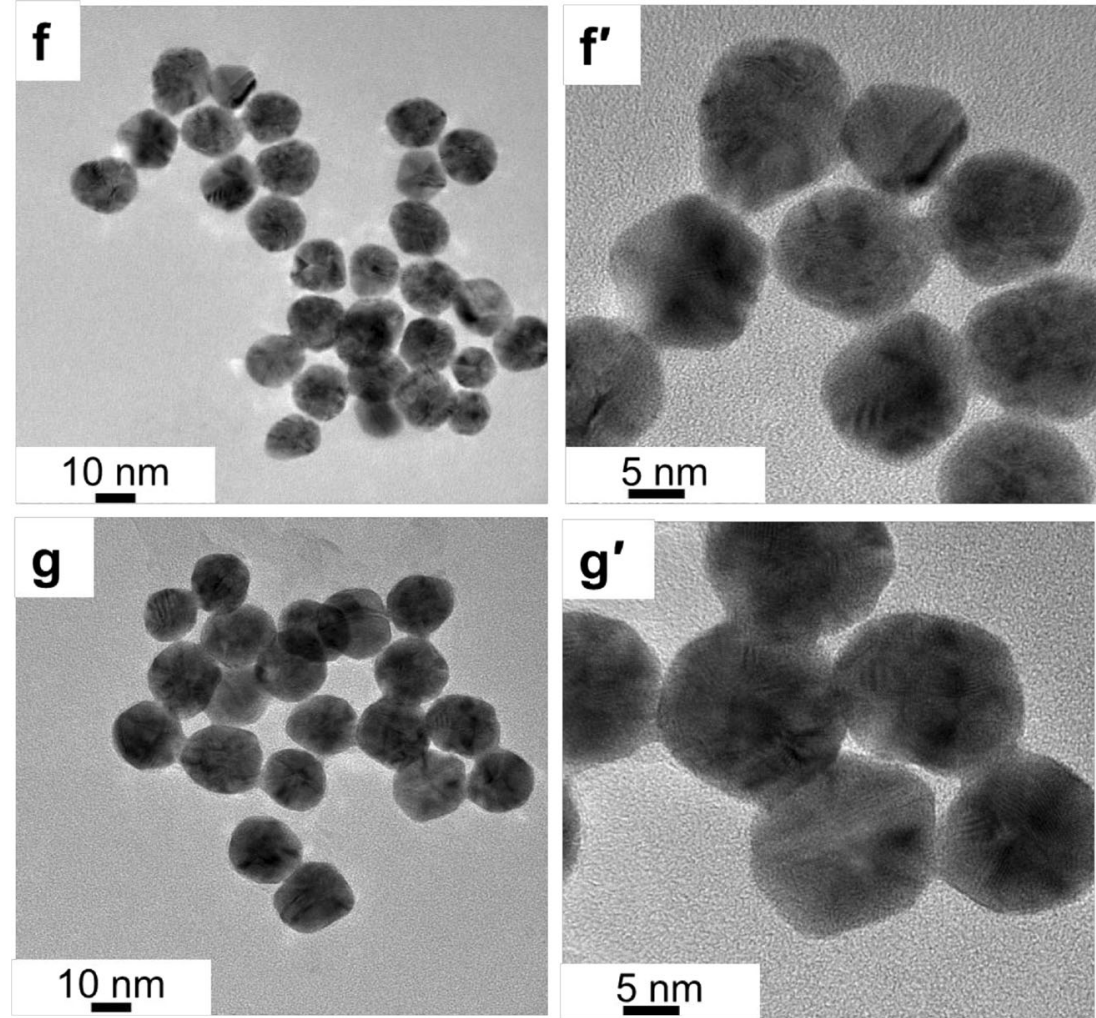

the surface of mono-dispersed $\mathrm{Au}$ seeds rather than forming separate AuNP seeds in the growth solution. As a result, good mono-dispersion of larger AuNPs was achieved through this seed-mediated growth approach.

The UV spectra of the AuNPs grown with the two different volumes of seed solutions are similar even though their TEM images showed different sizes for the nanoparticles. In both cases, UV absorption peaks appeared at 299, 399, and $530 \mathrm{~nm}$ (data not shown). Fluorescence spectra of both types of AuNPs were thus recorded with $\lambda_{\text {ex }}$ at 299 and $399 \mathrm{~nm}$. They both displayed emission peaks at 408 and $516 \mathrm{~nm}$ with $\lambda_{\text {ex }}$ of $299 \mathrm{~nm}$ (data not shown). The emission intensity at $408 \mathrm{~nm}$ of the AuNPs grown from $5 \mathrm{ml}$ of the seeds, however, is a little higher than that of the AuNPs grown from $2.5 \mathrm{ml}$. For the emission spectra with a $\lambda_{\text {ex }}$ of $399 \mathrm{~nm}$, only one emission peak, at $508 \mathrm{~nm}$, appeared for both types of AuNPs (data not shown), and for each type, the intensity of this peak is much lower than that with a $\lambda_{\text {ex }}$ of $299 \mathrm{~nm}$. The emission intensities of these PA-capped AuNPs grown using seeding were observed to be significantly higher than the emission intensities of citrate-capped AuNPs and lower than that of the original PA-capped AuNPs. These studies again prove that the florescence intensity has been increased with decreasing the size of spherical PAcapped AuNPs.

\section{Conclusions}

The effect of $\mathrm{pH}$ on the size of the PA-capped AuNP has been studied. TEM images show that the sizes of the AuNPs increased when the $\mathrm{pH}$ was decreased. By controlling the $\mathrm{pH}$, the sizes of the AuNPs became tunable from 10.7 to $75.6 \mathrm{~nm}$. The different sizes of the spherical AuNPs were also achieved by a seed-mediated growth approach. The fluorescence emission spectra of different AuNPs at different excitation wavelengths were measured. All the PA-capped AuNPs showed significantly higher fluorescence intensities than did the citrate-capped AuNPs, with the original PAcapped AuNPs showing the highest intensities among the prepared AuNPs. In addition, the PA-capped AuNPs showed higher zeta potentials, i.e., higher stabilities of the AuNPs compared to those of citrate-capped AuNPs. The findings of this work could be of interest for the simple preparation of other metal NPs, such as silver and platinum NPs, with different sizes, high colloidal stability, and good fluorescence properties.

Open Access This article is distributed under the terms of the Creative Commons Attribution 4.0 International License (http:// creativecommons.org/licenses/by/4.0/), which permits unrestricted use, distribution, and reproduction in any medium, provided you give appropriate credit to the original author(s) and the source, provide a link to the Creative Commons license, and indicate if changes were made. 


\section{References}

1. Tomar A, Garg G (2013) Glob J Pharmacol 7:34-38

2. Cai W, Gao T, Hong H, Sun J (2008) Nanotechnol Sci Appl 1:17-32

3. Saha K, Agasti SS, Kim C, Li X, Rotello VM (2012) Chem Rev 112:2739-2779

4. Aziz MA, Patra S, Yang H (2008) Chem Commun:4607-4609

5. Matsuoka K, Miyazaki K, Iriyama Y, Kikuchi K, Abe T, Ogumi Z (2007) J Phys Chem C 111:3171-3174

6. Cattin L, Tougaard S, Stephant N, Morsli S, Bernède JC (2011) Gold Bull 44:199-205

7. Mikami Y, Dhakshinamoorthy A, Alvaro M, Garcia H (2013) Catal Sci Technol 3:58-69

8. Sharma V, Park K, Srinivasarao M (2009) Mater Sci Eng R 65:1-38

9. Brülle T, Ju W, Niedermayr P, Denisenko A, Paschos O, Schneider O, Stimming U (2011) Molecules 16:10059-10077

10. Hebié S, Kokoh KB, Servat K, Napporn TW (2013) Gold Bull 46: 311-318

11. Frens G (1973) Nature Phys Sci 241:20-22

12. Ji X, Song X, Li J, Bai Y, Yang W, Peng X (2007) J Am Chem Soc 129:13939-13948

13. Li C, Li D, Wan G, Xu J, Hou W (2011) Nanoscale Res Lett 6:440

14. Bakshi MS, Sachar S, Kaur G, Bhandari P, Kaur G, Biesinger MC, Possmayer F, Petersen NO (2008) Cryst Growth Des 8:1713-1719

15. Kumar SV, Ganesan S (2011) Int J Green Nanotechnol 3:47-55

16. Londhe PU, More M, Chaure NB (2013) Proceedings of the "International Conference on Advanced Nanomaterials \& Emerging Engineering Technologies" (ICANMEET-20 13), Chennai, India in association with DRDO, New Delhi, India, 24th-26th, July: 317-319
17. Park G, Seo D, Chung IS, Song H (2013) Langmuir 29:1351813526

18. Dumur F, Guerlin A, Dumas E, Bertin D, Gigmes D, Mayer CR (2011) Gold Bull 44:119-137

19. Rawat KA, Surati KR, Kailasa SK (2014) Anal Methods 6:59725980

20. Choi Y, Choi M, Cha S, Kim YS, Cho S, Park Y (2014) Nanoscale Res Lett 9:103

21. Aziz MA, Kim J, Oyama M (2014) Gold Bull 47:127-132

22. Baghel GS, Rao CP (2009) Polyhedron 28:3507-3514

23. Guo Y, Wang Z, Shao H, Jiang X (2012) Analyst 137:301-304

24. Vázquez-González M, Carrillo-Carrion C (2014) J Biomed Opt 19: 101503-1-12

25. Gyanan, Khatei J (2014) Soft Nanosci Lett 4:69-74

26. Jiang C, Xu S, Yang D, Zhang F, Wang W (2007) Luminescence 22:430-437

27. Chitra K, Annadurai G (2013) J Nanotechnol. doi:10.1155/2013/ 509628

28. Mérian J, Gravier J, Navarro F, Texier I (2012) Molecules 17:5564 5591

29. Xie J, Zheng Y, Ying JY (2009) J Am Chem Soc 131:888-889

30. Duan H, Nie S (2007) J Am Chem Soc 129:2412-2413

31. Hill HD, Mirkin CA (2006) Nat Protoc 1:324-336

32. Abdelhalim MAK, Mady MM, Ghannam MM (2012) J Nanomed Nanotechol 3:133. doi:10.4172/2157-7439.1000133

33. Aslan K, Lakowicz JR, Geddes CD (2005) Anal Bioanal Chem 382:926-933

34. Kasture M, Sastry M, Prasad BLV (2010) Chem Phys Lett 484: $271-275$ 